\title{
Coronary Artery Aneurysm after Second-Generation Drug-Eluting Stent Implantation
}

\author{
Sung-Jin Hong ${ }^{1 *}$, Hyoeun Kim ${ }^{1 *}$, Chul-Min Ahn ${ }^{1}$, Jung-Sun Kim ${ }^{1}$, Byeong-Keuk Kim ${ }^{1}$, Young-Guk Ko ${ }^{1}$, \\ Bum-Kee Hong ${ }^{2}$, Donghoon Choi ${ }^{1,3}$, Yangsoo Jang ${ }^{1,3}$, and Myeong-Ki Hong ${ }^{1,3}$ \\ ${ }^{1}$ Division of Cardiology, Department of Internal Medicine, Severance Cardiovascular Hospital, Yonsei University Health System, Seoul; \\ ${ }^{2}$ Division of Cardiology, Department of Internal Medicine, Gangnam Severance Hospital, Seoul; \\ ${ }^{3}$ Cardiovascular Research Institute, Yonsei University College of Medicine, Seoul, Korea.
}

Purpose: We evaluated the incidence, predictors, and prognosis of coronary artery aneurysm (CAA) after second-generation drug-eluting stent (DES) implantation.

Materials and Methods: A total of 976 consecutive patients (1245 lesions) who underwent follow-up angiography after secondgeneration DES implantation were analyzed. Incidence and predictors of CAA were assessed, and clinical prognosis was compared with 34 cases of CAA after first-generation DES implantation using previous CAA registry data.

Results: All 10 cases of CAA ( $0.80 \%$ per lesion) in 10 patients (1.02\% per patient) were detected at follow up. Compared to lesions without CAA, those with CAA had greater involvement of the proximal segment ( $90 \%$ vs. $51 \%, p=0.014)$, a higher proportion of pre-intervention, a Thrombolysis in Myocardial Infarction score of 0 or 1 flow ( $80 \%$ vs. $16 \%, p<0.001)$, more chronic total occlusions ( $40 \%$ vs. $10 \%, p<0.001$ ), and longer implanted stents ( $41.9 \pm 23.2 \mathrm{~mm}$ vs. $28.8 \pm 14.8 \mathrm{~mm}, p=0.006$ ). As for CAA morphology, instances of CAA after second-generation DES were predominantly the single fusiform type (90\%), whereas instances of CAA after first-generation DES were multiple saccular (47\%) and single saccular (35\%) types $(p<0.001)$. Myocardial infarction with stent thrombosis occurred in 5 patients with CAA after first-generation DES (15\%), and no adverse events were observed in patients with CAA after second-generation DES over a median follow-up duration of 4.3 years ( $p=0.047$, log-rank).

Conclusion: Although CAAs after second-generation DES implantation were detected at a similar incidence to that for CAAs after first-generation DES implantation, second-generation DES-related CAAs had different morphologies and more benign clinical outcomes versus first-generation DES-related CAAs.

Key Words: Coronary artery disease, drug-eluting stent, percutaneous coronary intervention

\section{INTRODUCTION}

The onset of coronary artery aneurysm (CAA) after drug-elut-

Received: April 22, 2019 Revised: June 25, 2019

Accepted: July 11, 2019

Corresponding author: Myeong-Ki Hong, MD, PhD, Division of Cardiology, Department of Internal Medicine, Severance Cardiovascular Hospital, Yonsei University Health System, 50-1 Yonsei-ro, Seodaemun-gu, Seoul 03722, Korea.

Tel: 82-2-2228-8458, Fax: 82-2-2227-7732, E-mail: mkhong61@yuhs.ac

*Sung-Jin Hong and Hyoeun Kim contributed equally to this work.

-The authors have no potential conflicts of interest to disclose.

(C) Copyright: Yonsei University College of Medicine 2019

This is an Open Access article distributed under the terms of the Creative Commons Attribution Non-Commercial License (https://creativecommons.org/licenses/ by-nc/4.0) which permits unrestricted non-commercial use, distribution, and reproduction in any medium, provided the original work is properly cited. ing stent (DES) implantation is uncommon, with an incidence ranging from $0.8 \%$ to $1.3 \%$. However, associated adverse clinical events may present as a result of DES thrombosis and restenosis. ${ }^{1-4}$ Furthermore, the occurrence of DES thrombosis appears to be particularly high in patients with CAA who discontinued dual-antiplatelet therapy. ${ }^{4}$ Importantly, most previous studies have been conducted involving patients treated with first-generation DES implantation alone and, although concerns about the development of CAA after DES implantation have decreased after the introduction of second-generation DESs, occurrences of CAA even after second-generation DES implantation have been reported in recent case reports. ${ }^{5-7}$ At this time, to our knowledge, the incidence of CAA after second-generation DES implantation has not been evaluated, and even more concerning, the clinical implications of angiograph- 
ic CAA after second-generation DES placement remain uncertain. Therefore, we sought to evaluate the incidence and predictors of CAAs after second-generation DES implantation and to compare clinical outcomes in these patients with those of patients with CAAs after first-generation DES implantation using data from our CAA registry. ${ }^{4}$

\section{MATERIALS AND METHODS}

\section{Study population}

This study was a single-center, retrospective, observational study. Between August 2006 and August 2018, a total of 11982 consecutive patients underwent second-generation DES implantation (Fig. 1). Of these 11982 patients, 976 patients $(8.1 \%)$ with 1245 lesions underwent follow-up angiography within 2 years of second-generation DES placement, including 816 patients $(\mathbf{8 3 . 6 \%})$ for routine follow-up without any symptoms and 160 patients (16.4\%) for the evaluation of newly-developed symptoms, respectively. To compare with CAAs after first-generation DES implantation, angiographic data and clinical outcomes of 34 first-generation DES-related CAAs were obtained from our previous CAA registry data (Fig. 1). ${ }^{4}$ Briefly, these registry data from four independent referral hospitals in South Korea included 3612 consecutive patients (4419 lesions) with late angiographic follow up after first-generation DES implantation, which represented $58.4 \%$ of the larger initial population. In this subpopulation, 34 CAAs $(0.77 \%)$ in 29 patients $(0.80 \%)$ were detected during late follow-up angiography. ${ }^{4}$ This study was approved by the Institutional Review Board of Severance Hospital, Yonsei University Health System (No.: 4-2018-0759).

\section{Intervention procedure}

Stent implantation was performed according to current stan- dard techniques and medical guidelines. A total of 1245 lesions were treated with second-generation DESs: 425 everolimuseluting (Xience, Abbot Vascular, Santa Clara, CA, USA; and Promus, Boston Scientific, Marlborough, MA, USA), 399 zotarolimus-eluting (Endeavor Resolute, Medtronic, Minneapolis, MN, USA), 89 sirolimus-eluting (Orsiro, Biotronik, Berlin, Germany), and 332 biolimus-eluting (BioMatrix, Biosensors International, Singapore; and Nobori, Terumo, Tokyo, Japan) stents were used.

All patients were given $300 \mathrm{mg}$ of aspirin in addition to 300 $\mathrm{mg}$ to $600 \mathrm{mg}$ of clopidogrel, $180 \mathrm{mg}$ of ticagrelor, or $60 \mathrm{mg}$ of prasugrel before their procedure and were maintained on dualantiplatelet therapy after DES implantation for at least 6 months. During the intervention, unfractionated heparin was administered to maintain an activated clotting time of more than 250 seconds. Specific details of the intervention, such as lesion predilatation, poststent dilation, and the application of mechanical support or concomitant medication, were left to the discretion of the operator.

\section{Definition and clinical follow up}

A dilatation of a major epicardial, stented coronary artery that exceeded the diameter of the normal adjacent reference vessel by 1.5 times that was closely related to the underlying DES or its edges and was not present immediately after the procedure was defined as CAA. ${ }^{1,4}$ According to a previous study, ${ }^{4}$ CAAs can be classified into three different types: (1) ectatic type, a diffuse aneurysmal dilatation of the coronary artery that involves more than $50 \%$ of the stent length; (2) fusiform type, a spindle-shaped dilatation (along the axis of a vessel with at least twice the diameter of the transverse dimension); and (3) saccular type, a single or multiple spherical-shaped dilatation (the transverse dimension is usually greater than the longitudinal dimension). ${ }^{4}$

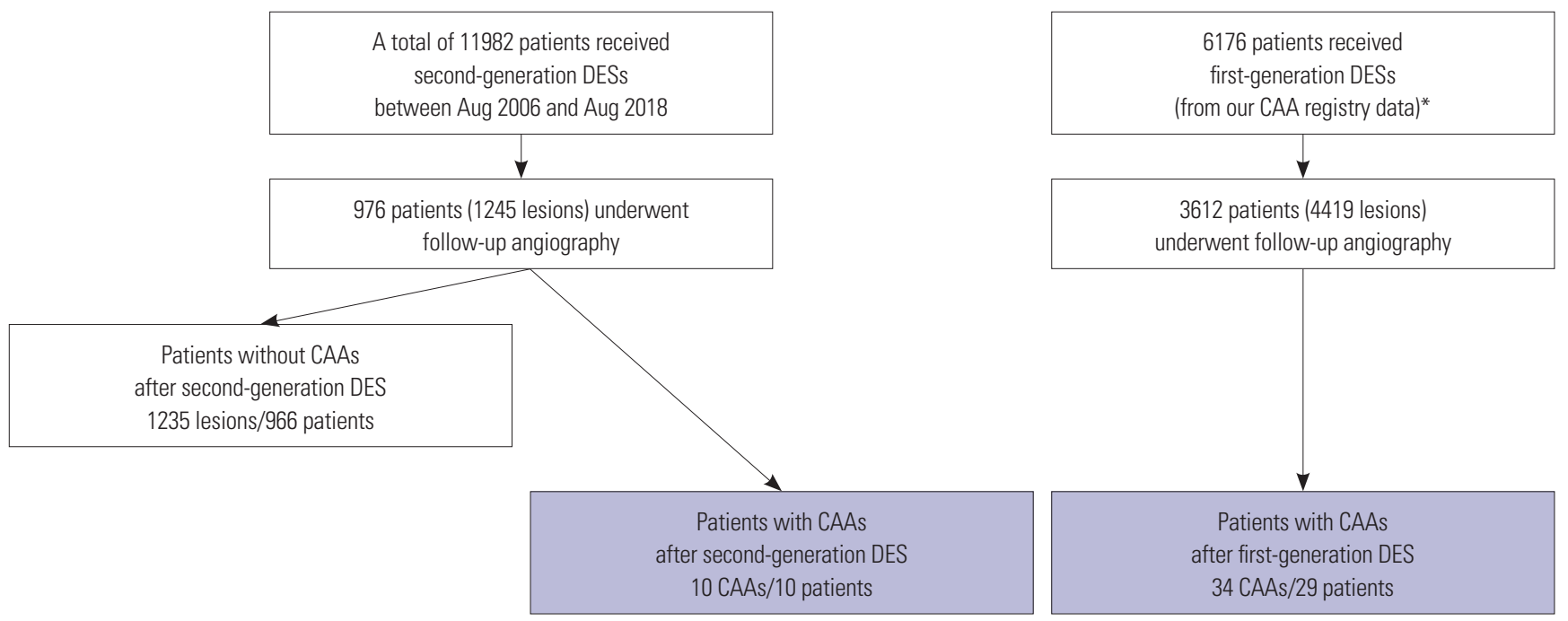

Fig. 1. Study population. *Angiographic data and clinical outcomes of 34 coronary artery aneurysms (CAAs) after first-generation drug-eluting stent (DES) were obtained from our CAA registry data. Aug, August. 
A major adverse cardiac event (MACE) was defined as a composite of cardiac death, myocardial infarction, and stent thrombosis. All deaths were considered cardiac deaths unless a definite noncardiac cause could be established. After hospital discharge, myocardial infarction was defined as the presence of consistent clinical symptoms, electrocardiographic changes, or abnormal imaging findings in combination with a creatine kinase myocardial band fraction increase of greater than the upper normal limit or an increase in troponin $\mathrm{T}$ or troponin I to more than the 99th percentile of the upper normal limit.,9 The Academic Research Consortium definition of definitive or probable stent thrombosis was used., ${ }^{4,8}$

\section{Statistical analysis}

Continuous variables are reported as a mean \pm standard deviation or median (interquartile range) as appropriate and were compared using Student's t-test or the Mann-Whitney U test. Categorical variables are reported as either a number or number (percentage) and were compared using Fisher's exact test or the chi-squared test. Adverse event rates were compared using a log-rank test. Findings were considered significant at $p<0.05$. All statistical analyses were performed using the Statistical Package for the Social Sciences, version 18.0 (SPSS Inc., Chicago, IL, USA).

\section{RESULTS}

Among 976 consecutive patients (1245 lesions) who underwent follow-up angiography, a total of 10 CAAs $(0.80 \%$ per le- sion) in 10 patients ( $1.02 \%$ per patient) were detected at followup after second-generation DES implantation with a median implanted time of 329 days (interquartile range: $210-403$ days). The individual profiles and angiographic morphologies of these patients with CAA are shown in Table 1 and Fig. 2. The incidence of CAA after second-generation DES implantation was similar to that of CAA after first-generation DES implantation according to our previous registry data $(0.77 \%$ per lesion and $0.80 \%$ per patient). ${ }^{4}$

Clinical characteristics between the patients with CAA $(n=10)$ and those without CAA ( $n=966)$ after second-generation DES placement are presented in Table 2 . There were no statistically significant differences in clinical characteristics between the two groups. Angiographic and procedural characteristics between the lesions with and without CAA after second-generation DES implantation are also presented in Table 3. In comparison with the lesions without CAA, those with CAA had more proximal lesions than mid-to-distal lesions ( $90 \%$ vs. $51 \%, p=$ 0.014), a higher proportion of pre-intervention Thrombolysis in Myocardial Infarction (TIMI) scores of 0 or 1 flow ( $80 \%$ vs. $16 \%, p<0.001$ ), and more chronic total occlusions ( $40 \%$ vs. $10 \%$, $p<0.001)$. Also, total stent length was significantly longer in the lesions with CAA versus those without CAA $(41.9 \pm 23.2 \mathrm{~mm}$ vs. $28.8 \pm 14.8 \mathrm{~mm}, p=0.006)$. When compared to the lesions with CAA after first-generation DES implantation $(\mathrm{n}=34)$ (Table 4), those with CAA after second-generation DES implantation had a significantly higher proportion of pre-intervention TIMI scores of 0 or 1 flow ( $80 \%$ vs. $12 \%, p<0.001$ ), more chronic total occlu-

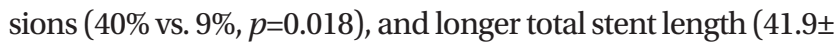
$23.2 \mathrm{~mm}$ vs. $28.0 \pm 5.0 \mathrm{~mm}, p=0.002)$.

Table 1. Individual Profiles of 10 CAAs after Second-Generation DES Implantation

\begin{tabular}{|c|c|c|c|c|c|c|c|c|c|c|}
\hline & & & & & Case & No. & & & & \\
\hline & 1 & 2 & 3 & 4 & 5 & 6 & 7 & 8 & 9 & 10 \\
\hline Age (yr) & 64 & 50 & 71 & 43 & 73 & 42 & 89 & 67 & 72 & 60 \\
\hline Sex & M & M & $\mathrm{F}$ & M & $\mathrm{F}$ & M & M & $\mathrm{F}$ & $\mathrm{F}$ & $\mathrm{F}$ \\
\hline Clinical diagnosis at index $\mathrm{PCl}$ & SA & STEMI & SA & SA & UA & STEMI & STEMI & SA & SA & NSTEMI \\
\hline Treated coronary artery & RCA & LCX & $L A D$ & $\mathrm{RCA}$ & $\mathrm{RCA}$ & $L A D$ & RCA & RCA & $L A D$ & RCA \\
\hline Proximity of lesions & Yes & Yes & Yes & Yes & Yes & No & Yes & Yes & Yes & Yes \\
\hline ACC/AHA lesion classification & $C$ & C & C & C & C & C & B2 & C & C & C \\
\hline Chronic total occlusion & Yes & No & Yes & Yes & No & No & No & Yes & No & No \\
\hline Days from index PCI to diagnosis of CAA & 368 & 264 & 289 & 385 & 412 & 79 & 69 & 210 & 403 & 588 \\
\hline Morphology of CAA & Fusiform & Fusiform & Fusiform & Fusiform & Fusiform & $\begin{array}{l}\text { Multiple } \\
\text { saccular }\end{array}$ & Fusiform & Fusiform & Fusiform & Fusiform \\
\hline Location of CAA relative to stent & Mid & Mid & Mid & Mid & $\begin{array}{l}\text { Proximal } \\
\text { edge }\end{array}$ & Mid & $\begin{array}{l}\text { Proximal } \\
\text { edge }\end{array}$ & Mid & $\begin{array}{l}\text { Proximal } \\
\text { edge }\end{array}$ & Mid \\
\hline Follow-up days after diagnosis of CAA & 1594 & 2517 & 1574 & 2732 & 2306 & 1849 & 1044 & 1363 & 1013 & 515 \\
\hline $\begin{array}{l}\text { Days of maintained dual-antiplatelet } \\
\text { therapy after diagnosis of CAA }\end{array}$ & $0^{*}$ & 925 & 43 & $428^{*}$ & $0^{*}$ & 372 & 598 & 15 & 574 & 105 \\
\hline
\end{tabular}



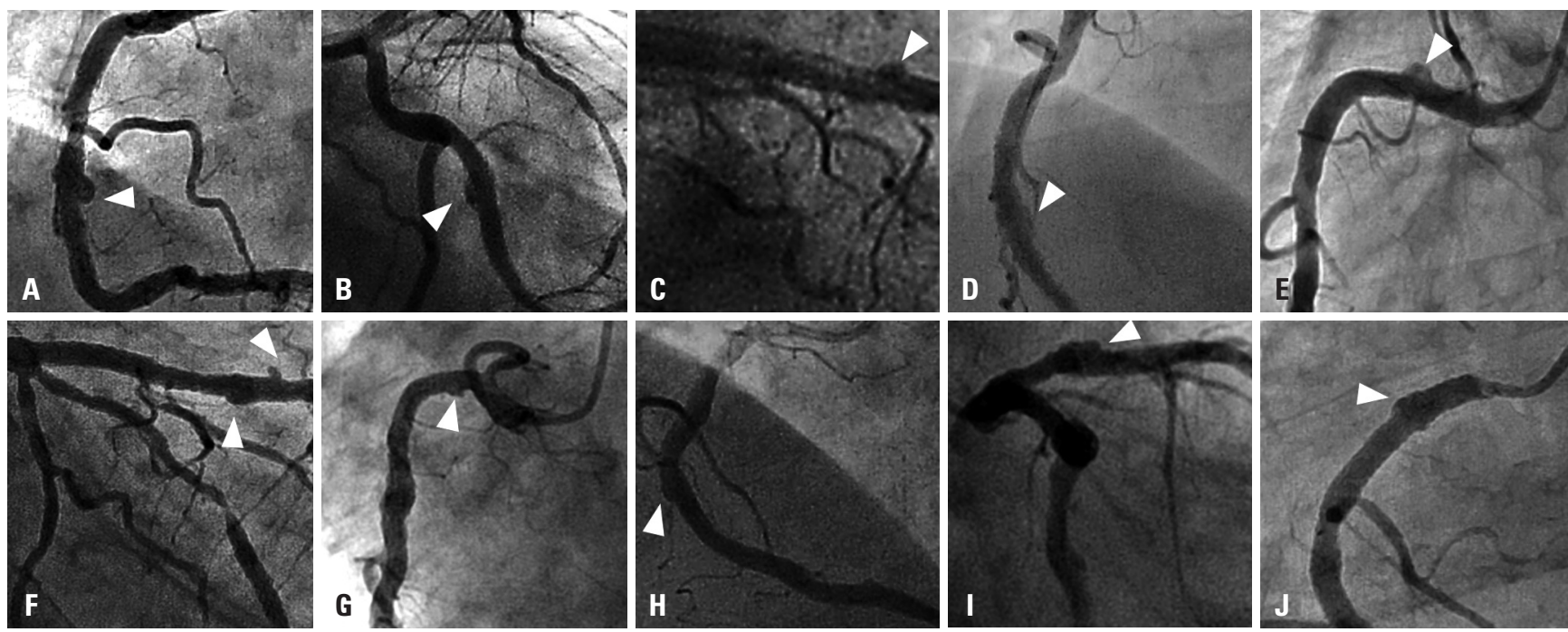

Fig. 2. (A-J) Individual morphologies of 10 coronary artery aneurysms (CAAs) (Case 1 through Case 10) after second-generation drug-eluting stent (DES) implantation. White arrowheads indicate the development of CAAs. Detailed individual data are also presented in Table 1.

Table 2. Clinical Characteristics between Patients with and without CAAs after Second-Generation Drug-Eluting Stent Implantation

\begin{tabular}{lccc}
\hline & $\begin{array}{c}\text { With CAA } \\
(\mathbf{n = 1 0 )}\end{array}$ & $\begin{array}{c}\text { Without } \\
\text { CAA } \\
(\mathbf{n}=966)\end{array}$ & p value \\
\hline Age $(\mathrm{yr})$ & $63 \pm 15$ & $63 \pm 11$ & 0.944 \\
\hline Body mass index $\left(\mathrm{kg} / \mathrm{m}^{2}\right)$ & $24.7 \pm 4.6$ & $24.6 \pm 3.1$ & 0.991 \\
\hline Men (n, \%) & $5(50)$ & $726(75)$ & 0.068 \\
\hline Hypertension (n, \%) & $5(50)$ & $640(66)$ & 0.280 \\
\hline Diabetes mellitus (n, \%) & $3(30)$ & $357(37)$ & 0.650 \\
\hline Chronic kidney disease (n, \%) & 0 & $38(4)$ & 0.522 \\
\hline Current smoker (n, \%) & $4(40)$ & $282(29)$ & 0.455 \\
\hline Dyslipidemia (n, \%) & $7(70)$ & $691(72)$ & 0.915 \\
\hline Left ventricular ejection fraction (\%) & $61.8 \pm 12.858 .8 \pm 12.3$ & 0.451 \\
\hline Clinical diagnosis at index procedure (n, \%) & & & 0.474 \\
\hline Stable angina & $5(50)$ & $465(48)$ & \\
\hline Unstable angina & $1(10)$ & $213(22)$ & \\
\hline Non-ST-elevation myocardial infarction & $1(10)$ & $149(16)$ & \\
\hline ST-elevation myocardial infarction & $3(30)$ & $139(14)$ & \\
\hline Severity of coronary artery disease (n, \%) & & & 0.685 \\
\hline 1-vessel disease & $1(10)$ & $166(17)$ & \\
\hline 2-vessel disease & $3(30)$ & $347(36)$ & \\
\hline 3-vessel disease & $6(60)$ & $453(47)$ & \\
\hline CAA, & & & \\
\hline
\end{tabular}

CAA, coronary artery aneurysm.

Values are presented as mean \pm standard deviation or $n(\%)$ unless otherwise indicated.

As for CAA morphology, the predominant form of CAA after second-generation DES implantation was significantly different from that of CAA after first-generation DES implantation $(p<0.001)$ (Table 4, Fig. 3A). CAAs after second-generation DES placement were predominantly of the single fusiform type (90\%), whereas CAAs after first-generation DES placement were multiple saccular (47\%) and single saccular (35\%) types.
The clinical outcomes of CAA according to DES generation are presented in Table 5 and Fig. 3B. During a median followup of 309 days (interquartile range: 16-581 days) after CAA detection following first-generation DES implantation, a total of five cases with CAA (15\%) experienced MACE. ${ }^{4}$ These five adverse events were related to acute myocardial infarction with definite or probable stent thrombosis. ${ }^{4}$ However, during a median follow-up of 1584 days (interquartile range: 1044-2306 days), no patients with CAA had MACE, and one patient with CAA received target lesion revascularization at the time of CAA detection (case 4 in Table 1, Supplementary Fig. 1, only online). Thus, CAAs after first-generation DES implantation had significantly higher MACE rates than did those after second-generation DES implantation ( $p$ value by log-rank $=0.047$ ). The duration of dual-antiplatelet therapy after CAA detection was not different between CAAs after second-generation DES implantation versus those after first-generation DES implantation $(p=0.847)$.

\section{DISCUSSION}

The major findings of our study are that (1) CAAs after secondgeneration DES implantation were detected at incidence rates of $0.80 \%$ per lesion and $1.02 \%$ per patient, which were higher than values associated with CAA after first-generation DES implantation; (2) after implantation of second-generation DESs, CAAs were more frequently detected in correlation with the treatment of more complex lesions (e.g., pre-intervention TIMI flow grade 0 or 1 , chronic total occlusions, and longer implanted stents); and (3) CAAs after second-generation DES implantation had different morphologies and might have more favorable clinical outcomes, compared with those after first-generation DES implantation. 
Table 3. Angiographic Characteristics between Lesions with and without CAAs after Second-Generation DES

\begin{tabular}{|c|c|c|c|}
\hline & $\begin{array}{c}\text { With CAA } \\
\qquad(n=10)\end{array}$ & $\begin{array}{c}\text { Without } \\
\text { CAA } \\
(n=1235)\end{array}$ & $p$ value \\
\hline Treated coronary arteries (n, \%) & & & 0.250 \\
\hline Left main & 0 & $72(6)$ & \\
\hline Left anterior descending & $3(30)$ & $526(43)$ & \\
\hline Left circumflex & $1(10)$ & $252(20)$ & \\
\hline Right coronary & $6(60)$ & $385(31)$ & \\
\hline Proximity of lesions (n, \%) & & & 0.014 \\
\hline Proximal & $9(90)$ & $632(51)$ & \\
\hline Mid-to-distal & $1(10)$ & $603(49)$ & \\
\hline ACC/AHA lesion classification (n, \%) & & & 0.065 \\
\hline Type B1 & 0 & $100(8)$ & \\
\hline Type B2 & $1(10)$ & $542(44)$ & \\
\hline Type C & $9(90)$ & $586(47)$ & \\
\hline Pre-intervention TIMI flow grade (n, \%) & & & $<0.001$ \\
\hline $0 / 1$ & $8(80)$ & $193(16)$ & \\
\hline $2 / 3$ & $2(20)$ & 1042 (84) & \\
\hline Use of rotablation (n, \%) & 0 & $17(1)$ & - \\
\hline Bifurcation (n, \%) & $1(10)$ & $386(31)$ & 0.148 \\
\hline Chronic total occlusion (n, \%) & $4(40)$ & $117(10)$ & 0.001 \\
\hline Thrombus (n, \%) & $2(20)$ & $130(11)$ & 0.333 \\
\hline Total stent length & $41.9 \pm 23.2$ & $28.8 \pm 14.8$ & 0.006 \\
\hline Total stent number (n, \%) & & & $<0.001$ \\
\hline 1 & $5(50)$ & $1040(84)$ & \\
\hline 2 & $3(30)$ & $176(14)$ & \\
\hline 3 & $2(20)$ & $19(2)$ & \\
\hline Mean stent diameter & $3.10 \pm 0.37$ & $3.06 \pm 0.41$ & 0.784 \\
\hline Type of second-generation DES (n, \%) & & & 0.974 \\
\hline Everolimus-eluting stent & $3(30)$ & $422(34)$ & \\
\hline Zotarolimus-eluting stent & $3(30)$ & $396(32)$ & \\
\hline Sirolimus-eluting stent & $1(10)$ & $88(7)$ & \\
\hline Biolimus-eluting stent & $3(30)$ & $329(27)$ & \\
\hline
\end{tabular}

CAA, coronary artery aneurysm; DES, drug-eluting stent; ACC/AHA, American College of Cardiology/American Heart Association; TIMI, Thrombolysis in Myocardial Infarction.

Values are presented as mean \pm standard deviation or $\mathrm{n}(\%)$ unless otherwise indicated.

Although the exact mechanisms remain unclear, several causes of CAAs have been suggested to date. The mechanical risk factors for CAAs after coronary intervention include arterial wall injury as well as dissection or rupture induced by high-pressure balloon inflation or oversized stent. Atherectomy and laser angioplasty have additionally been associated with the development of CAAs. ${ }^{10,11}$ Therefore, our findings of the predictors of CAAs after second-generation DES implantation, specifically more complex lesions, such as chronic total occlusions or those requiring longer stents, may be line with the suggested mechanisms. Similar to these findings, CAA development after first-generation DES placement was related to more severe complex lesions. Our previous registry data also indicat- ed that the CAA development after first-generation DES placement occurs exclusively in complex (type B2/C) de novo lesions and that lesion length is significantly greater in patients with CAA than in those without CAA. ${ }^{4}$ Interestingly, when we compared the observed CAAs present after second-generation DES implantation and those present after first-generation DES implantation, the CAAs after second-generation DES placement also had more complex lesions than did those after first-generation DES placement.

Other factors for the development of CAAs have also been proposed due to DES implantation. ${ }^{1-4}$ DESs have been used for reducing restenosis by administration of cytotoxic anti-restenosis drugs to inhibit endothelial cell and smooth muscle cell proliferation, and these antiproliferative effects have been suggested to increase the risk of CAAs because of the mechanism of delayed neointimal healing and reendotheliazation. ${ }^{12,13}$ Separately, a local hypersensitivity reaction to the polymer of the drug in the DESs may contribute to CCAs. The inflammatory response to the drugs increased eosinophilic or heterophilic infiltration into the vessel, as well as the occurrence of local toxic effects. These mechanisms induce weakening and disruption of the arterial wall, provoking arterial wall expansion and aneurysmal change. ${ }^{13-15}$ Although concerns about the development of CAAs after DES placement have decreased with greater use of second-generation DESs, these limitations still can be related to CAA onset even in the context of second-generation DES implantation. In our study, we documented incidence rates of CAAs after second-generation DES implantation of $0.80 \%$ per lesion and $1.02 \%$ per patient. According to previous reports on first-generation DESs, CAAs were detected with an incidence of $0.8 \%$ to $1.3 \% .^{1-4}$ Such numbers are relatively comparable to those regarding CAAs after second-generation DES use. However, importantly, different than the CAAs after firstgeneration implantation, the CAAs after second-generation implantation had different predominant morphologies and more favorable outcomes, reflecting the advances in DES technology. According to recent studies involving first-generation DESs, CAAs are frequently associated with adverse clinical events as a result of DES thrombosis and restenosis. ${ }^{1-4}$ In one investigation, Alfonso, et al. ${ }^{1}$ found that, of 1197 patents with first-generation DESs, CAAs developed in 15 patients (1.25\%) and the 1 -year adverse event rate was $51 \%$. Joo, et al. ${ }^{3}$ followed up 78 patients with CAA after first-generation DES implantation and determined that the patients with CAAs displayed a significantly higher incidence of MACE than did those without CAAs, driven by target-lesion revascularization and myocardial infarction. Lastly, from our CAA registry of first-generation DESs, myocardial infarction with stent thrombosis occurred in $17.2 \%$ of the cases with CAA with $75 \%$ being on aspirin alone without clopidogrel. ${ }^{4}$ However, notably, all three of these studies were conducted in patients treated with first-generation DES placement.

Our current study has some limitations. First, although we 
Sung-Jin Hong, et al.

Table 4. Angiographic Characteristics between Lesions with CAAs after First-Generation DES and Second-Generation DES

\begin{tabular}{|c|c|c|c|}
\hline & CAA after second-generation DES ( $n=10)$ & CAA after first-generation DES ( $n=34$ ) & $p$ value \\
\hline \multicolumn{4}{|l|}{ At index PCl } \\
\hline Treated coronary artery (n, \%) & & & 0.016 \\
\hline Left anterior descending & $3(30)$ & $25(74)$ & \\
\hline Left circumflex & $1(10)$ & 0 & \\
\hline Right coronary & $6(60)$ & $9(26)$ & \\
\hline Proximity of lesions (n, \%) & & & 0.275 \\
\hline Proximal & $9(90)$ & $9(26)$ & \\
\hline Mid-to-distal & $1(10)$ & $25(74)$ & \\
\hline ACC/AHA lesion classification (n, \%) & & & 0.553 \\
\hline Type B1 & 0 & $3(9)$ & \\
\hline Type B2 & $1(10)$ & $5(15)$ & \\
\hline Type C & $9(90)$ & $26(76)$ & \\
\hline Pre-intervention TIMI flow grade (n, \%) & & & $<0.001$ \\
\hline $0 / 1$ & $8(80)$ & $4(12)$ & \\
\hline $2 / 3$ & $2(20)$ & $30(88)$ & \\
\hline Chronic total occlusion (n, \%) & $4(40)$ & $3(9)$ & 0.018 \\
\hline Total stent length (mm) & $41.9 \pm 23.2$ & $28.0 \pm 5.0$ & 0.002 \\
\hline Mean stent diameter (mm) & $3.1 \pm 0.4$ & $3.1 \pm 0.3$ & 0.909 \\
\hline Stent type & & & - \\
\hline \multicolumn{4}{|l|}{ First-generation DES (n, \%) } \\
\hline Sirolimus-eluting stent & - & $25(74)$ & \\
\hline Paclitaxel-eluting stent & - & $9(26)$ & \\
\hline \multicolumn{4}{|l|}{ Second-generation DES (n, \%) } \\
\hline Everolimus-eluting stent & $3(30)$ & - & \\
\hline Zotarolimus-eluting stent & $3(30)$ & - & \\
\hline Sirolimus-eluting stent & $1(10)$ & - & \\
\hline Biolimus-eluting stent & $3(30)$ & - & \\
\hline \multicolumn{4}{|l|}{ At diagnosis of CAA } \\
\hline $\begin{array}{l}\text { Days from PCI to CAA detection } \\
\text { [median (interquartile range)] }\end{array}$ & $329(210-403)$ & $385(260-481)$ & 0.170 \\
\hline Morphologic classification (n, \%) & & & $<0.001$ \\
\hline Ectasia & 0 & $3(9)$ & \\
\hline Fusiform & $9(90)$ & $3(9)$ & \\
\hline \multicolumn{4}{|l|}{ Saccular } \\
\hline Single & 0 & $12(35)$ & \\
\hline Multiple & $1(10)$ & $16(47)$ & \\
\hline
\end{tabular}

CAA, coronary artery aneurysm; DES, drug-eluting stent; PCl, percutaneous coronary intervention; ACC/AHA, American College of Cardiology/American Heart Association; TIMI, Thrombolysis in Myocardial Infarction.

Values are presented as mean \pm standard deviation or $\mathrm{n}(\%)$ unless otherwise indicated.

enrolled consecutive patients with follow-up angiography in our study, the percentages and indications were not pre-specified and differed from the cohorts with CAAs after first-generation DES placement. Also, selection bias is inevitable because all patients did not undergo follow-up angiography in our study. Second, a relatively small number of patients was analyzed, necessitating a larger group of initial follow-up patients to be studied for further confirmation. Also, the followup duration of the CAA after first-generation DES was shorter than that of the CAA after second-generation DES, because our previous CAA registry of the first-generation DES was not extended for longer follow up. Third, our patients did not undergo invasive intracoronary imaging studies, though these studies would be helpful to observe the development of lateacquired stent malapposition due to CAA.

In conclusion, CAAs after second-generation DES implantation were detected rarely at a similar incidence to that of CAAs after first-generation DES implantation. However, patients with second-generation DESs might demonstrate more favorable clinical outcomes, compared to those after firstgeneration DES implantation. 


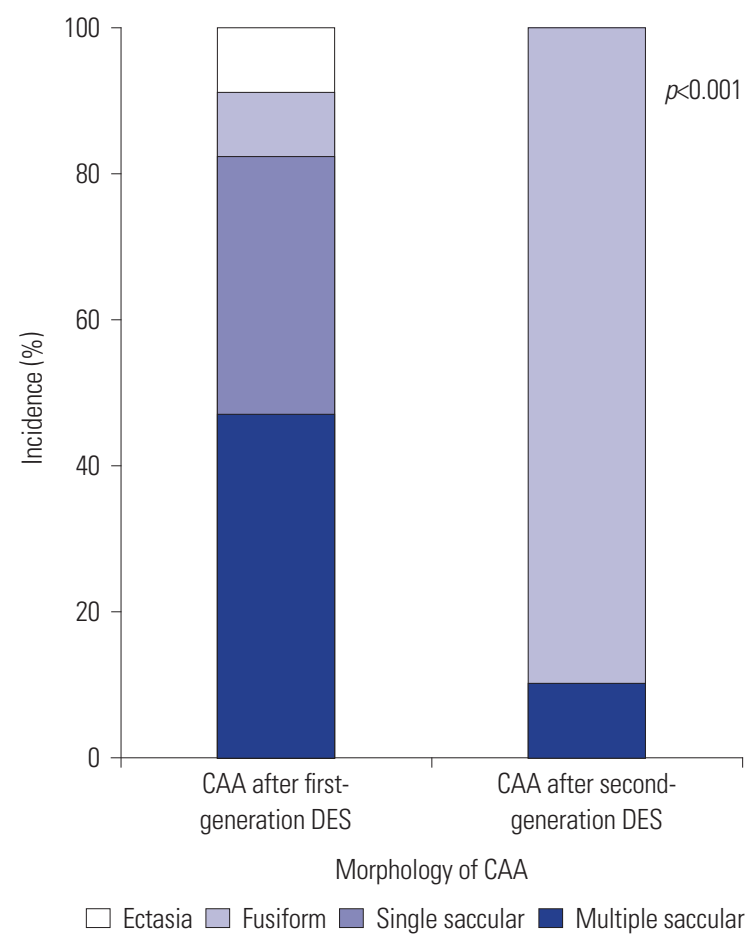

A

Fig. 3. (A) Morphologic classification of coronary artery aneurysms (CAAs) according to drug-eluting stent (DES) generation. (B) Clinical outcomes of CAAs according to DES generation. Major adverse cardiac event (MACE) included the composite of cardiac death, myocardial infarction, and stent thrombosis. PCl, percutaneous coronary intervention.

Table 5. Comparison of Clinical Outcomes between Patients with CAA after First-Generation DES and Those with CAA after Second-Generation DES

\begin{tabular}{|c|c|c|c|}
\hline & $\begin{array}{l}\text { CAA after second-generation DES } \\
(\mathrm{n}=10)\end{array}$ & $\begin{array}{l}\text { CAA after first-generation DES } \\
(\mathrm{n}=34)\end{array}$ & $p$ value \\
\hline Follow-up days after CAA detection [median (interquartile range)] & $1584(1044-2306)$ & $309(16-581)$ & $<0.001$ \\
\hline Days of DAPT after CAA detection [median (interquartile range)] & $239(15-574)$ & $161(0-564)$ & 0.843 \\
\hline Major adverse cardiac event (n, \%) & 0 & $5(15)$ & $0.047^{*}$ \\
\hline Cardiac death (n, \%) & 0 & 0 & - \\
\hline Acute myocardial infarction (n, \%) & 0 & $5(15)$ & $0.047^{*}$ \\
\hline ST-elevation myocardial infarction & 0 & 2 & - \\
\hline Non-ST-elevation myocardial infarction & 0 & 3 & - \\
\hline Definite or probable stent thrombosis (n, \%) & 0 & $5(15)$ & $0.047^{*}$ \\
\hline Target lesion revascularization (n, \%) & $1(10)$ & $5(15)$ & $0.291 *$ \\
\hline
\end{tabular}

CAA, coronary artery aneurysm; DES, drug-eluting stent; DAPT, dual antiplatelet therapy.

Values are presented as $\mathrm{n}(\%)$ unless otherwise indicated.

*B By log-rank test.

\section{ACKNOWLEDGEMENTS}

This study was supported by a grant from the Korea Healthcare Technology Research \& Development Project, Ministry for Health \& Welfare, Republic of Korea (nos. A085136 and HI15C1277); the Mid-Career Research Program through a National Research Foundation grant funded by the Ministry of Education, Science and Technology, Republic of Korea (no. 2015R1A2A2A01002731); and the Cardiovascular Research Center, Seoul, Korea.

\section{AUTHOR CONTRIBUTIONS}

Conceptualization: Sung-Jin Hong, Hyoeun Kim, and Myeong-Ki Hong. Data curation: Sung-Jin Hong, Hyoeun Kim, Chul-Min Ahn, Bum-Kee Hong, and Myeong-Ki Hong. Formal analysis: Sung-Jin Hong and Hyoeun Kim. Funding acquisition: Jung-Sun Kim, ByeongKeuk Kim, Young-Guk Ko, Bum-Kee Hong, Donghoon Choi, Yangsoo Jang, and Myeong-Ki Hong. Investigation: Bum-Kee Hong, Donghoon Choi, Yangsoo Jang, and Myeong-Ki Hong. Methodology: SungJin Hong, Hyoeun Kim, Chul-Min Ahn, Bum-Kee Hong, and MyeongKi Hong. Project administration: Sung-Jin Hong, Hyoeun Kim, ChulMin Ahn, Bum-Kee Hong, and Myeong-Ki Hong. Resources: SungJin Hong, Hyoeun Kim, Chul-Min Ahn, Bum-Kee Hong, and Myeong- 
Ki Hong. Software: Sung-Jin Hong, Hyoeun Kim, Chul-Min Ahn, Bum-Kee Hong, and Myeong-Ki Hong. Supervision: All authors. Validation: All authors. Visualization: All authors. Writing—original draft: All authors. Writing — review \& editing: All authors.

\section{ORCID iDs}

Sung-Jin Hong Hyoeun Kim Chul-Min Ahn Jung-Sun Kim Byeong-Keuk Kim Young-Guk Ko Bum-Kee Hong Donghoon Choi Yangsoo Jang Myeong-Ki Hong

https://orcid.org/0000-0003-4893-039X https://orcid.org/0000-0002-7334-9700 https://orcid.org/0000-0002-7071-4370 https://orcid.org/0000-0003-2263-3274 https://orcid.org/0000-0003-2493-066X https://orcid.org/0000-0001-7748-5788 https://orcid.org/0000-0002-6456-0184 https://orcid.org/0000-0002-2009-9760 https://orcid.org/0000-0002-2169-3112 https://orcid.org/0000-0002-2090-2031

\section{REFERENCES}

1. Alfonso F, Pérez-Vizcayno MJ, Ruiz M, Suárez A, Cazares M, Hernández R, et al. Coronary aneurysms after drug-eluting stent implantation: clinical, angiographic, and intravascular ultrasound findings. J Am Coll Cardiol 2009;53:2053-60.

2. Aoki J, Kirtane A, Leon MB, Dangas G. Coronary artery aneurysms after drug-eluting stent implantation. JACC Cardiovasc Interv 2008;1:14-21.

3. Joo HJ, Yu CW, Choi R, Park J, Lee HJ, Kim JS, et al. Clinical outcomes of patients with coronary artery aneurysm after the first generation drug-eluting stent implantation. Catheter Cardiovasc Interv 2018;92:E235-245.

4. Ahn CM, Hong BK, Kim JY, Min PK, Yoon YW, Lee BK, et al. Incidence and natural history of coronary artery aneurysm developing after drug-eluting stent implantation. Am Heart J 2010;160:987-94.

5. Zbinden R, Eshtehardi P, Cook S. Coronary aneurysm formation in a patient early after everolimus-eluting stent implantation. J In- vasive Cardiol 2008;20:E174-5.

6. Kadakia MB, Epps KC, Julien ME, Ogbara J, Giri J, Kolansky DM, et al. Early aneurysm formation after everolimus-eluting stent implantation. Circ Cardiovasc Interv 2014;7:266-7.

7. Goldberg A, Zdorovyak A, Rosenfeld I, Nordkin I. Early development of coronary artery aneurysms after implantation of biolimus-eluting stent with biodegradable polymer. Int J Cardiol 2015; 184:487-8.

8. Cutlip DE, Windecker S, Mehran R, Boam A, Cohen DJ, van Es GA, et al. Clinical end points in coronary stent trials: a case for standardized definitions. Circulation 2007;115:2344-51.

9. Thygesen K, Alpert JS, Jaffe AS, Chaitman BR, Bax JJ, Morrow DA, et al. Fourth universal definition of myocardial infarction (2018). J Am Coll Cardiol 2018;72:2231-64.

10. Slota PA, Fischman DL, Savage MP, Rake R, Goldberg S. Frequency and outcome of development of coronary artery aneurysm after intracoronary stent placement and angioplasty. Am J Cardiol 1997;79:1104-6.

11. Bell MR, Garratt KN, Bresnahan JF, Edwards WD, Holmes DR Jr. Relation of deep arterial resection and coronary artery aneurysms after directional coronary atherectomy. J Am Coll Cardiol 1992; 20:1474-81.

12. Rab ST, King SB 3rd, Roubin GS, Carlin S, Hearn JA, Douglas JS Jr. Coronary aneurysms after stent placement: a suggestion of altered vessel wall healing in the presence of anti-inflammatory agents. J Am Coll Cardiol 1991;18:1524-8.

13. Finn AV, Nakazawa G, Joner M, Kolodgie FD, Mont EK, Gold HK, et al. Vascular responses to drug eluting stents: importance of delayed healing. Arterioscler Thromb Vasc Biol 2007;27:1500-10.

14. Stähli BE, Camici GG, Steffel J, Akhmedov A, Shojaati K, Graber $\mathrm{M}$, et al. Paclitaxel enhances thrombin-induced endothelial tissue factor expression via c-Jun terminal NH2 kinase activation. Circ Res 2006;99:149-55.

15. Hofma SH, van der Giessen WJ, van Dalen BM, Lemos PA, McFadden EP, Sianos G, et al. Indication of long-term endothelial dysfunction after sirolimus-eluting stent implantation. Eur Heart J 2006;27:166-70. 